\title{
Peripheral Blood and Ovarian Levels of Sex Steroids in the Lactating Rat
}

\author{
KAZUYOShi TAYA ${ }^{1}$ AND Gilbert S. GREENWALD \\ Department of Physiology, Ralph L. Smith Research Center, \\ University of Kansas Medical Center, Kansas City, \\ Kansas 66103, U.S.A.
}

\begin{abstract}

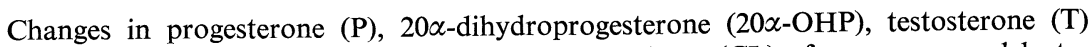
and estradiol-17 $\beta\left(\mathrm{E}_{2}\right)$ in peripheral blood, in corpora lutea (CL) of pregnancy and lactation and non-luteal ovarian tissues (NLO), and serum levels of LH, FSH and prolactin (PRL) were determined by radioimmunoassay in lactating rats nursing 8 pups. CL of pregnancy and lactation and NLO were removed at various days after post-partum ovulation (Day 0 of lactation $=$ day of parturition).

Serum $\mathrm{E}_{2}$ remained low until Day 10 of lactation followed by a slight increase from Days 12 to 21. Serum $T$ was unchanged throughout lactation. Low levels of $T$ and $E_{2}$ in NLO were observed until Day 12, followed by a gradual increase on Day 15 and onward. These changes correlated with low levels of serum LH from Days 2 to 12 and a return to basal levels on Days 15 to 21 . Throughout lactation serum FSH remained at basal levels corresponding to diestrous values during the estrous cycle. High levels of serum PRL were observed from Days 4 to 10 . Serum levels of $\mathbf{P}$ reached maximal values between Days 8 and 10 and decreased after Day 12. Changes in serum $20 \alpha-\mathrm{OHP}$ were inversely related to serum $\mathrm{P}$ throughout lactation. The CL of pregnancy contained large amounts of $20 \alpha-$ OHP and small amounts of P on Days 1 and 2 followed by an abrupt decline until Day 21 . On the other hand, a marked increase in content and concentration of $\mathrm{P}$ in the CL of lactation occurred between Days 6 and 12 followed by a gradual decline by Day 21 . Content and concentration of $20 \alpha-\mathrm{OHP}$ in the CL of lactation increased progressively from Day 1 to 21 .

These findings indicate that the CL of pregnancy secrete a large amount of $20 \alpha-\mathrm{OHP}$ and a small amount of $\mathrm{P}$ during the early stages of lactation. Thereafter, the CL of lactation markedly increase their ability to secrete P. High levels of P and PRL during the first half of lactation along with strong suckling stimuli may be involved in the suppression of follicular development, presumably by lowering basal levels of serum LH.
\end{abstract}

During lactation in the rat, striking changes in ovarian histology occur, i.e. prolonged anovulation depending on the size of the litter and atrophy of the corpora lutea (CL) of pregnancy, while $\mathrm{CL}$ of lactation resulting

\section{Received May 10, 1982}

1 Present address: Laboratory of Veterinary Physiology, Faculty of Agriculture, Tokyo University of Agriculture and Technology, Fuchu, Tokyo 183, Japan. To whom reprints should be requested. from post-partum ovulation increase their size and secretion of progesterone (P). However, $\mathrm{CL}$ of pregnancy are of considerable size during the early stages of lactation. Following post-partum ovulation, the number of healthy follicles in the ovary decreases and the number of atretic follicles markedly increases during the early stages of lactation in rats nursing 8 pups, whereas a few large healthy follicles are always present in the late stages of lactation (Taya and Sasamoto, 1981). Despite the 
great deal of work which has been done on the hypothalamic-hypophysial function during lactation in the rat, relatively little attention has been directed towards correlating serum levels of steroids with the steroidogenic capacity of the ovary in toto or the CL of pregnancy and lactation and the non-luteal ovarian tissues (NLO) to secrete steroids. The present study was therefore undertaken to provide a comprehensive account of changes in ovarian steroidogenesis throughout lactation in the rat by determining $\mathrm{P}, 20 \alpha$-dihydroprogesterone (20 $\alpha$-OHP), testosterone (T) and estradiol$17 \beta\left(\mathrm{E}_{2}\right)$ in serum and in isolated CL of pregnancy and lactation and NLO. To complete the picture, serum levels of gonadotropins were also measured.

\section{Materials and Methods}

\begin{abstract}
Animals
Pregnant rats of the Holtzman strain with known dates of insemination were obtained from SASCO (Omaha, Nebraska) and were maintained in an environmentally controlled room illuminated daily from 0500 to $1900 \mathrm{~h}$. They were placed in separate cages 5 days before parturition. The day of parturition was designated as Day 0 of lactation and the litter was adjusted to 8 pups. Any mother not having 8 pups was discarded. Between 0900 and $1000 \mathrm{~h}$ on the days of lactation indicated on the graphs, mothers were decapitated. Blood was collected and serum saved for radioimmunoassay (RIA) of $\mathrm{P}, 20 \alpha-\mathrm{OHP}, \mathrm{T}, \mathrm{E}_{2}, \mathrm{LH}$, FSH and prolastin (PRL). Immediately after blood collection, the ovaries were removed and placed in ice cold saline and all CL of pregnancy and lactation, as judged by their size and vascularity, were separated using jeweler's forceps with a dissecting microscope and cleaned of adhering ovarian tissue. From each animal 4-5 CL of pregnancy and lactation were selected at random. After weighing, the CL (2.4-23.4 mg) and the resultant NLO $(7.4-27.3 \mathrm{mg})$ were placed in $0.4 \mathrm{ml}$ $95 \%$ ethanol for steroid determinations. All tissues were homogenized in $95 \%$ ethanol and stored at $-20^{\circ} \mathrm{C}$ until used for estimations of steroids.
\end{abstract}

\section{Steroids RIAs}

The RIAs for steroids were the same as described previously (Terranova and Greenwald, 1978) using P antisera (Surve et al., 1976), $\mathrm{T}$ antisera (Pang and Johnson, 1974) and $\mathrm{E}_{2}$ antisera (Exley et al., 1971). Since $\mathbf{T}$ antiserum cross reacts with $5 \alpha$-dihydrotesto- sterone $(58 \%)$ and androstendione $(2 \%)$ the steroid levels are referred to as testosterone-equivalents. The antiserum to $20 \alpha$-OHP was supplied by Drs. C. N. Pang and J. Hilliard (University of California at Los Angeles) and the only steroid which cross reacted (> $1 \%$ ) with the antiserum was $20 \beta$-dihydroprogesterone $(42 \%)$. The lower limits of sensitivity in the assay for $\mathrm{P}, 20 \alpha-\mathrm{OHP}, \mathrm{T}$ and $\mathrm{E}_{2}$ were $5 \mathrm{pg}, 5 \mathrm{pg}, 2 \mathrm{pg}$ and $2 \mathrm{pg}$ per tube, respectively.

\section{Gonadotropin RIAs}

LH, FSH and PRL were determined in sera by RIA, using kits provided by NIAMDD. The methods were similar to those of Bast and Greenwald (1974). Antisera used were anti-rat LH serum 3, anti-rat FSH serum 9 and anti-rat PRL serum 4. Reference preparations used for standards were rat LH-RP-1 $(0.03 \times$ NIH-LH-S1), FSH-RP-1 (2.1 $\times$ NIH-FSH-S1) and PRLRP-1 (11 i.u./mg). Iodinated preparations were rat LH-I-1, FSH-I-1 and PRL-I-3. In the LH and FSH assay, $200 \mu \mathrm{l}$ sera were used whereas in PRL assays, 25 and $50 \mu 1$ were assayed, respectively. Duplicate serum samples were assayed. The lower limit of assay sensitivity for LH, FSH and PRL was $0.5 \mathrm{ng}, 6.3 \mathrm{ng}$ and $0.06 \mathrm{ng}$ per tube, respectively.

\section{Statistics}

The significance of difference between two means was tested by Student's $t$-test, but when more than two means were compared an analysis of variance was carried out and the significance of the difference between means was determined by Duncan's multiple range test (Steel and Torrie, 1960). Differences were judged significant if $\mathrm{P}<0.05$.

\section{Results}

Changes in weight of $C L$ of pregnancy and lactation and NLO (Fig. 1)

Post-partum ovulation occurred within 24 $\mathrm{h}$ after parturition with comparable number of oocytes shed $(12.7 \pm 0.6, \mathrm{n}=6)$ to cyclic animals $(12.2 \pm 0.6, \mathrm{n}=6)$. After parturition, the weight of the CL of pregnancy declined rapidly by Day 10, then continued to decrease gradually until Day 21 . In contrast, the weight of CL of lactation increased steadily from the day of ovulation (Day 1) to the end of lactation (Day 21), although the maximum weight was only one half that of the CL of pregnancy. After parturition, the weight of NLO rapidly decreased by Day 4 and remained the same thereafter. 

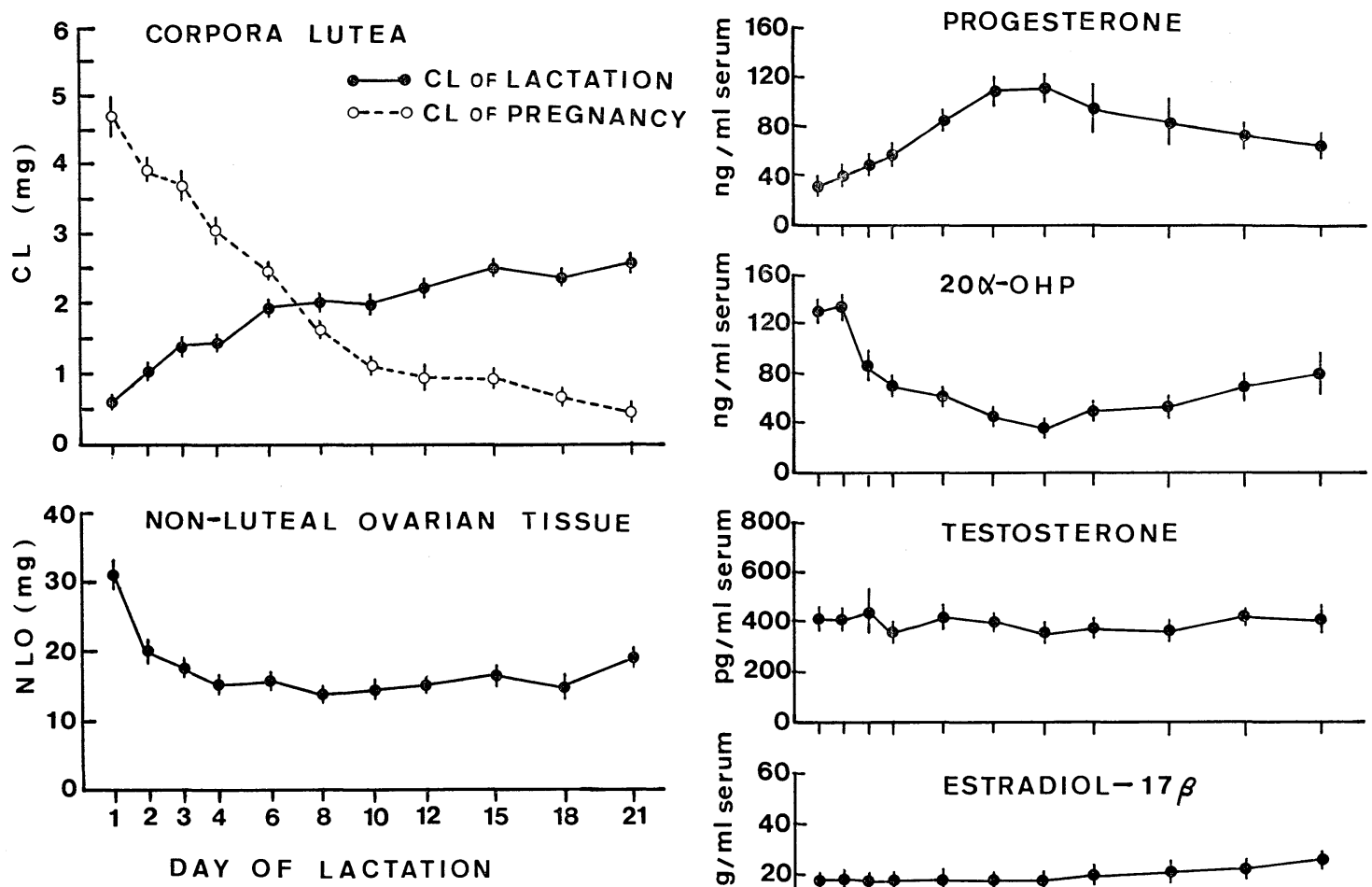

Fig. 1. Changes in weight of corpus luteum (CL) of pregnancy and lactation and non-luteal ovarian tissue (NLO) during lactation in the rat. In all figures, results are expressed as mean \pm S.E.M. for 6 animals/group.

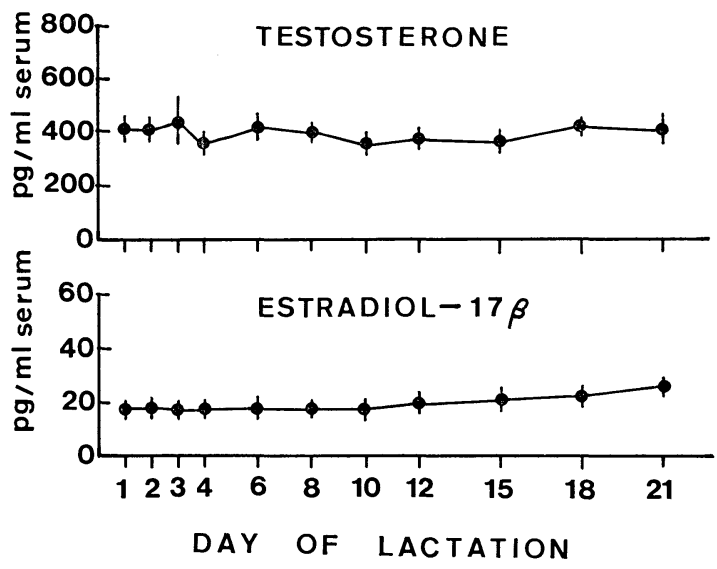

Fig. 2. Serum levels of $P, 20 \alpha-O H P, T$ and $E_{2}$ during lactation in the rat.

Serum levels of steroids (Fig. 2)

Serum $\mathrm{P}$ gradually increased from Days 1 to 10 with the maximum value reached on Day 10 with the levels then decreasing slowly by Day 21. In contrast, serum levels of $20 \alpha$ OHP were high on Days 1 and 2 followed by an abrupt decrease until Day 10. On Day 10, serum levels of $20 \alpha$-OHP were at their nadir and thereafter gradually increased.

Levels of serum $\mathrm{T}$ remained unchanged at about $400 \mathrm{pg} / \mathrm{ml}$ throughout lactation. Serum $\mathrm{E}_{2}$ was constantly low from Day 1 through Day 10 and then increased slightly from Day 12 to Day 21.

\section{Concentration of $T$ and $E_{2}$ in $N L O$ (Fig. 3)}

In general, throughout lactation the change

in non-luteal concentration of $\mathrm{T}$ was similar to that of $E_{2}$. The NLO concentrations of $T$ and $\mathrm{E}_{2}$ were low until Day 12, followed by an abrupt increase by Day 15 and a further increase by Day 21 .

Levels of $P$ and $20 \alpha-O H P$ in the $C L$ of pregnancy and lactation (Figs. 4 and 5)

Since the growth of the CL in the rat represents hypertrophy rather than hyperplasia, luteal levels of $\mathrm{P}$ and $20 \alpha-\mathrm{OHP}$ were calculated at the basis of content (per CL) or concentration (per mg CL).

On day 1 , the $C L$ of pregnancy contained small amounts of $\mathrm{P}$ and the content dropped progressively until Day 21, whereas the con- 


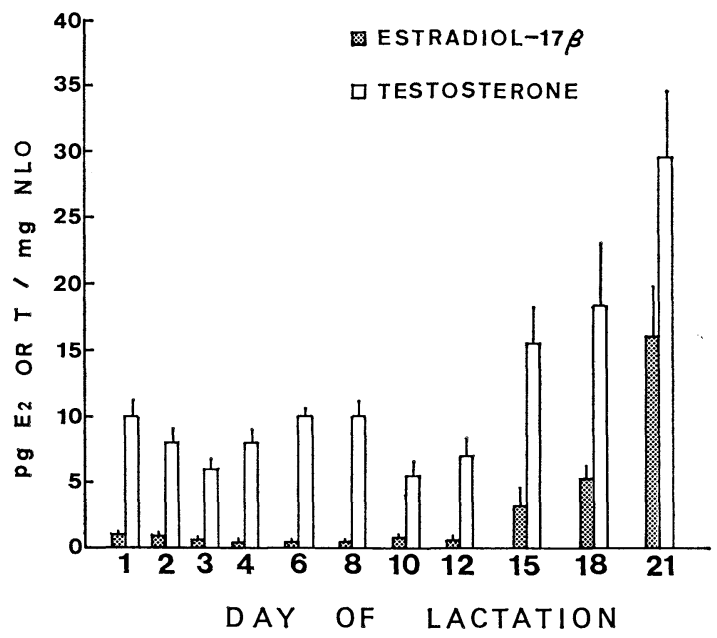

Fig. 3. Concentration of $\mathrm{T}$ and $\mathrm{E}_{2}$ in NLO during lactation in the rat.
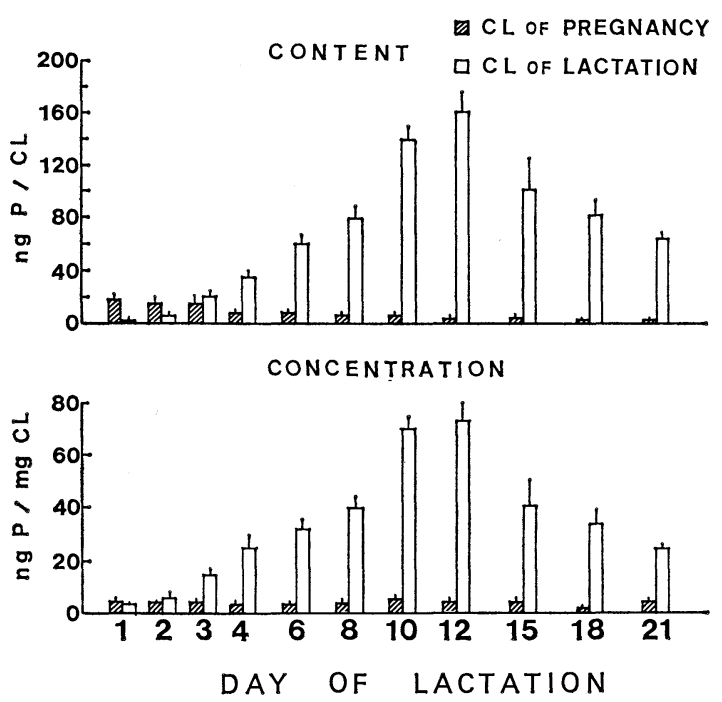

Fig. 4. Content and concentration of $\mathrm{P}$ in $\mathrm{CL}$ of pregnancy or lactation during lactation in the rat.

centration of the hormone was relatively constant throughout lactation (Fig. 4). On the other hand, on Days 1 and 2, the CL of pregnancy contained high amounts of $20 \alpha-\mathrm{OHP}$, but the content and concentration declined abruptly by Day 3. Thereafter the content of the hormone decreased gradually until Day
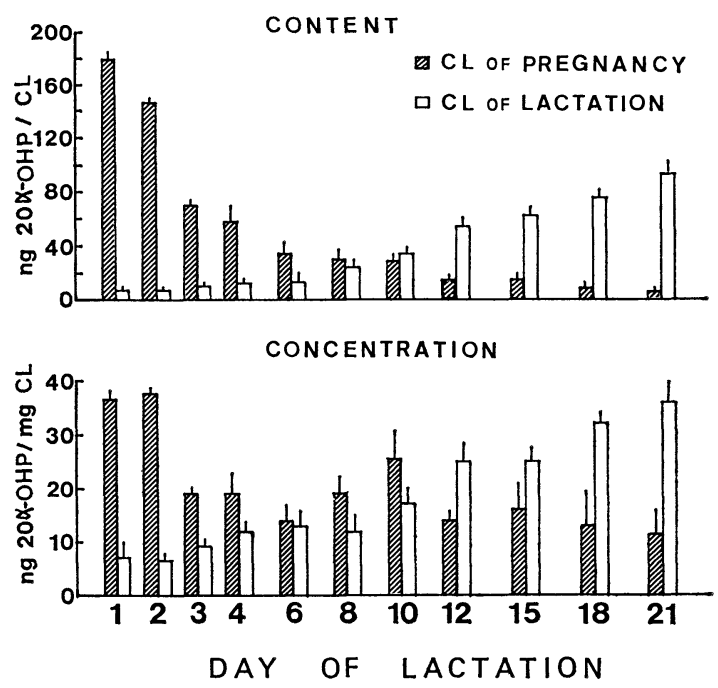

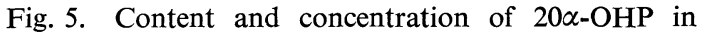
the $\mathrm{CL}$ of pregnancy or lactation during lactation in the rat.

21, whereas there was no significant decline when they were expressed as the concentration of the hormone (Fig. 5).

In contrast, luteal content and concentration of $\mathrm{P}$ in the $\mathrm{CL}$ of lactation significantly increased by Day 3 and continued to increase markedly until Day 12 (Fig. 4). Thereafter, luteal levels of $P$ in the $C L$ of lactation decreased gradually until Day 21 regardless of which way they were expressed. Although luteal content of $\mathbf{P}$ on Days 1 and 2 was significantly higher in the CL of pregnancy than the CL of lactation, the luteal concentration of the hormone was not different between the CL of pregnancy and lactation. After Day 4, luteal content and concentration of $\mathrm{P}$ in the $\mathrm{CL}$ of lactation was significantly higher than in the CL of pregnancy. Luteal levels of $20 \alpha-$ $\mathrm{OHP}$, in the CL of lactation increased gradually throughout lactation (Fig. 5). The maximal content and concentration of $20 \alpha-\mathrm{OHP}$ in the $\mathrm{CL}$ of lactation was noted on Day 21. On Days 1 through 4, luteal levels of $20 \alpha-O H P$ were significantly higher in the $\mathrm{CL}$ of pregnancy than in the CL of lactation, whereas 
after Day 12, the values were much higher in the $\mathrm{CL}$ of lactation compared to the $\mathrm{CL}$ of pregnancy.

\section{Serum levels of LH, FSH and PRL (Fig. 6)}

Serum levels of $\mathrm{LH}$ were relatively high on Day 1 and abruptly decreased by Day 2; the values were low from Days 2 to 12 compared to the diestrous levels of cyclic rats. A gradual rise in serum $\mathrm{LH}$ began after Day 15.

Relatively high levels of serum FSH were observed on Day 1. Thereafter, serum FSH was maintained at basal levels throughout the period of lactation comparable to diestrous values in the estrous cycle.

There was a marked increase in serum PRL on Day 4 and high levels were maintained
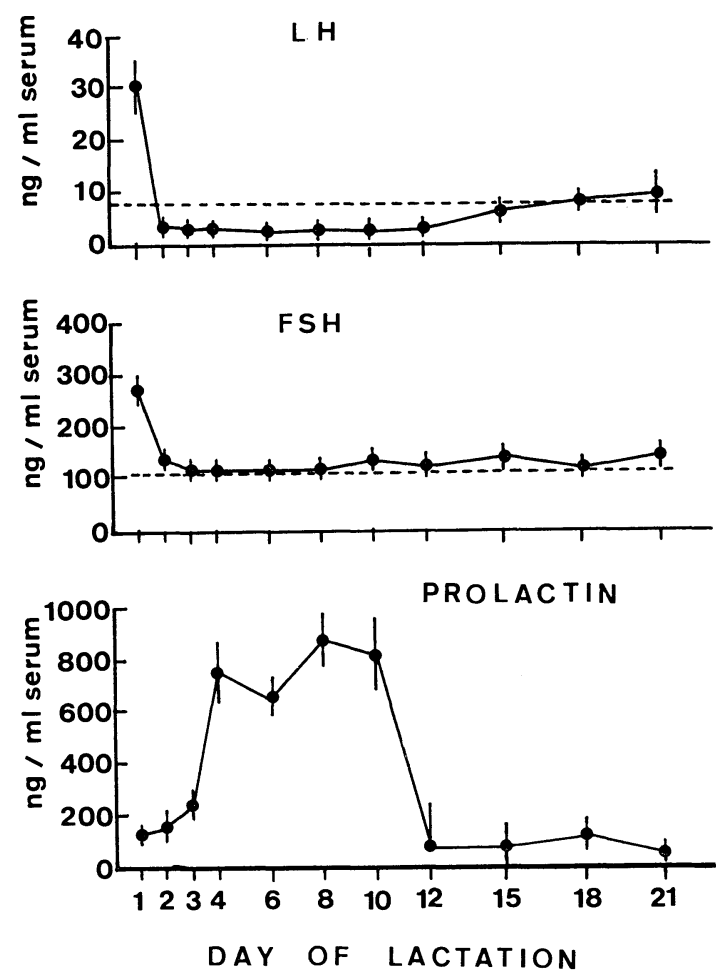

Fig. 6. Serum levels of LH, FSH and PRL during lactation in the rat. The dotted line of the graph represents the mean of the serum LH $(6.8 \pm 0.4, \mathrm{n}=$ 6) and FSH $(101.0 \pm 4.0, \mathrm{n}=6)$ levels at $0900 \mathrm{~h}$ on diestrus II of cyclic rats. until Day 10, followed by an abrupt decline by Day 12. Serum PRL was relatively constant from Day 12 to Day 21.

\section{Discussion}

In the present study, during the first half of lactation the low level of serum $E_{2}$ correlates with the absence of large antral follicles (Taya and Sasamoto, 1981). There were increased concentrations of $E_{2}$ and $T$ in NLO after Day 15 of lactation (Fig. 3), indicating that follicular maturation was then initiated. These results agree with previous findings that no ovulation in response to HCG was observed and no follicles of $401-500 \mu \mathrm{m}$ in diameter were present during the early stages of lactation, whereas ovulation is readily produced by HCG during the second half of lactation correlated with follicles larger than $401 \mu \mathrm{m}$ in diameter (Taya and Sasamoto, 1977; 1981). The serum levels of $E_{2}$ agree in general with previous findings that there are low levels of estrogen during the early stages of lactation (Smith and Neill, 1977). In the present study, serum $\mathrm{T}$ was unchanged throughout lactation. Serum levels of $\mathrm{T}$ during lactation have not been reported previously.

The marked reduction in $\mathrm{E}_{2}$ and $\mathrm{T}$ in NLO during the first half of lactation coincided with decreasing secretion of $\mathrm{LH}$ and increasing secretion of PRL whereas the secretion of FSH was unchanged (Figs. 3 and 6). The serum levels of FSH, LH and PRL (Fig. 6) agree with those of previous papers (Ford and Melampy, 1973; Smith and Neill, 1977; Taya and Sasamoto, 1981). These results suggest that decreasing serum levels of LH during the first half of lactation are insufficient to optimally support thecal cell synthesis of androgen and thus follicular $E_{2}$ secretion, since thecal cells have been shown to be the source of androgen precursors which are converted to estrogen by an FSH-dependent aromatizing enzyme system present in the granulosa cell (Erickson and Ryan, 1976; Fortune and 
Armstrong, 1977; Makris and Ryan, 1977; Tsang et al., 1979).

It has been well established that the active secretion of $\mathrm{P}$ by the CL of lactation during lactation can be ascribed to the luteotropic action of prolactin (Yoshinaga, 1974; Ford and Yoshinaga, 1975b; Tomogane et al., 1975). In the present study, the levels of $\mathrm{P}$ in serum and CL of lactation reached a peak on Days 10 and 12, respectively, and decreased gradually until the end of lactation. On the other hand, serum levels of PRL decreased abruptly on Day 12 and relatively low levels were maintained thereafter. The reason for the delayed response of luteal $\mathrm{P}$ secretion to an abrupt decline in serum PRL is not clear. In the present experiments, although the level of serum PRL was measured only at $0900 \mathrm{hr}$ on each day, van der Schoot et al. (1978) have reported that there were at least two diurnal peaks of serum PRL in post-parturient rats during the first 4 days after removal of a 10pup litter on Day 13 of lactation. Therefore, it is possible that nocturnal or diurnal increases in serum PRL may occur during the second half of lactation in lactating rats nursing 8 pups. It has also been reported that LH plays an important role in the secretion of $\mathrm{P}$ during lactation in the rat, since the administration of antisera against $\mathrm{LH}$ to lactating rats causes a decline in the concentration of $\mathrm{P}$ in ovarian venous blood (Yoshinaga et al., 1971; Ford and Yoshinaga, 1975a). Previous reports have demonstrated that the ability of LH to stimulate $\mathrm{P}$ is augmented by the presence of PRL (Armstrong et al., 1969; Wu and Wiest, 1976), most probably in increasing the number of $\mathrm{LH}$ receptors in the CL (Grinwich et al., 1976; Holt et al., 1976; Behrman et al., 1978). Serum levels of $20 \alpha$-OHP show an inverse relationship throughout lactation to serum $\mathrm{P}$ (Fig. 2). Our data also indicate that during the early stages of lactation the CL of pregnancy contain considerable amounts of $20 \alpha-$ OHP and small amounts of P. On the other hand, in the CL of lactation luteal levels of $\mathrm{P}$ and 20 $\alpha$-OHP increased gradually. These results clearly indicate that during the early stages of lactation the high levels of serum $20 \alpha$-OHP represent a proportionally larger contribution from the $\mathrm{CL}$ of pregnancy than the CL of lactation. Furthermore, the maximal content and concentration of $\mathrm{P}$ in $\mathrm{CL}$ of lactation are much greater than those of $\mathrm{CL}$ of pregnancy during gestation (Taya and Greenwald, 1981), though the CL of lactation are much smaller than the CL of pregnancy. Ford et al. (1975) have reported that the corpora lutea of pregnancy are the major contributor to ovarian $20 \alpha-\mathrm{OHP}$ secretion during midlactation using post-partum ovulation blocked rats by antisera against $\mathrm{LH}$ releasing hormone. The present results on changes in peripheral P and 20 $\alpha$-OHP levels agree in general with previous findings in the ovarian venous blood (Tomogane et al., 1969; Yoshinaga et al., 1971). During the first half of lactation, high levels of serum $\mathrm{P}$ secreted from the functional CL associated with the suckling stimulus and high levels of PRL may suppress serum $\mathrm{LH}$, since exogenous $\mathrm{P}$ injected into diestrous rats lowers serum $\mathrm{LH}$ within $1 \mathrm{~h}$ (Taya et al., 1981).

\section{Acknowledgements}

K.T. was supported as a Ford Foundation fellow in Reproductive Biology. The research was supported by a grant from NIH (HD 00596). We thank Dr. A. F. Parlow and the NIAMDD division of NIH for providing the rat RIA kits for LH, FSH and PRL. We wish to thank Dr. P. F. Terranova for helping with the gonadotropin RIAs. Our thanks are also due to Mrs. Darlene Limback for her excellent technical assistance.

\section{References}

Armstrong, D. T., L. S. Miller and K. A. Knudsen (1969). Regulation of lipid metabolism and progesterone production in rat corpora lutea and ovarian interstitial elements by prolactin and luteinizing hormone. Endocrinology 85, 393-401.

Bast, J. D. and G. S. Greenwald (1974). Serum profiles of follicle-stimulating hormone, luteinizing hormone and prolactin during the estrous cycle of 
the hamster. Endocrinology 94, 1295-1299.

Behrman, H. R., D. L. Grinwich, M. Hichens and G. J. Macdonald (1978). Effect of hypophysectomy, prolactin and prostaglandin $\mathrm{F} 2 \alpha$ on gonadotropin binding in vivo and in vitro in the corpus luteum. Endocrinology 103, 349-357.

Erickson, G. F. and K. J. Ryan (1976). Stimulation of testosterone production in isolated rabbit thecal tissue by LH/FSH, dibutyryl cyclic AMP, PGF $2 \alpha$ and PGE2. Endocrinology 99, 452-458.

Exley, D., M. W. Johnson and P. D. G. Dean (1971). Antisera highly specific for $17 \beta$-estradiol. Steroids 18, 605-620.

Ford, J. J. and R. M. Melampy (1973). Gonadotropin levels in lactating rats: effect of ovariectomy. Endocrinology 93, 540-547.

Ford, J. J. and K. Yoshinaga (1975a). The role of LH in the luteotrophic process of lactating rats. Endocrinology 96, 329-334.

Ford, J. J. and K. Yoshinaga (1975b). The role of prolactin in the luteotrophic process of lactating rats. Endocrinology 96, 335-339.

Ford, J. J., M. Takahashi, K. Yoshinaga and R. O. Greep (1975). Progestin levels after inhibition of postpartum ovulation in rats. Biol. Reprod. 12, 584-589.

Fortune, J. E. and D. T. Armstrong (1977). Androgen production by theca and granulosa isolated from proestrous rat follicles. Endocrinology 100, 13411347.

Grinwich, D. L., M. Hichens and H. R. Behrman (1976). Control of the LH receptor by prolactin and prostaglandin $\mathrm{F} 2 \alpha$ in rat corpora lutea. Biol. Reprod. 14, 212-218.

Holt, J. A., J. S. Richards, A. R. Jr. Midgley and L. E. Reichert (1976). Effect of prolactin on LH receptor in rat luteal cells. Endocrinology 98, 1005-1013.

Makris, A. and K. J. Ryan (1977). Aromatase activity of isolated and recombined hamster granulosa cells and theca. Steroids 29, 65-72.

Pang, C. N. and D. C. Johnson (1974). A method for preparation of steroid-protein antigens for use in immunoassay of steroids. Steroids 23, 203-219.

van der Schoot, P., R. R. Lankhorst, J. A. de Roo and W. J. de Greef (1978). Suckling stimulus, lactation, and suppression of ovulation in the rat. Endocrinology 103, 949-956.

Smith, M. S. and J. D. Neill (1977). Inhibition of gonadotropin secretion during lactation in the rat: relative contribution of suckling and ovarian steroids. Biol. Reprod. 17, 255-261.
Steel, R. G. D. and J. H. Torrie (1960). Principles and procedures of statistics. end 3, pp. 99-131.

Surve, A. H., I. Basco, J. H. Brinckerhoff and S. J. Kirsch (1976). Plasma levels of progesterone in pseudopregnant rabbits actively immunized with a progesterone protein conjugate. Biol. Reprod. 15, 343-349.

Taya, K. and G. S. Greenwald (1981). In vivo and in vitro ovarian steroidogenesis in the pregnant rat. Biol. Reprod. 25, 683-691.

Taya, K. and S. Sasamoto (1977). Induction of ovulation by exogenous gonadotrophin during pseudopregnancy, pregnancy or lactation in rats. J. Reprod. Fert. 51, 467-468.

Taya, K. and S. Sasamoto (1981). Changes in FSH, LH and prolactin secretion and ovarian follicular development during lactation in the rat. Endocrinol. Japon. 28, 187-196.

Taya, K., P. F. Terranova and G. S. Greenwald (1981). Acute effects of exogenous progesterone on follicular steroidogenesis in the cyclic rat. Endocrinology 108, 2324-2330.

Terranova, P. F. and G. S. Greenwald (1978). Steroid and gonadotropin levels during the luteal-follicular shift of the cyclic hamster. Biol. Reprod. 18, 170175.

Tomogane, H., K. Ota and A. Yokoyama (1969). Progesterone and 20 $\alpha$-hydroxypregn-4en-3one levels in ovarian vein blood of the rat throughout lactation. J. Endocrinol. 44, 101-106.

Tomogane, H., K. Ota and A. Yokoyama (1975). Suppression of progesterone secretion in lactating rats by administration of ergocornine and the effect of prolactin replacement. $J$. Endocrinol. 65, 155161.

Tsang, B. K., Y. S. Moon, C. W. Simpson and D. T. Armstrong (1979). Androgen biosynthesis in human follicles: cellular source gonadotropin control and adenosine $3^{\prime}, 5^{\prime}$-monophosphate mediation. $J$. Clin. Endocrinol. Metab. 48, 153-158.

Wu, D. H. and W. G. Wiest (1976). Luteotropic regulation of dispersed rat luteal cells in early pregnancy. Endocrinology 98, 1378-1389.

Yoshinaga, K. (1974). Ovarian progestin secretion in lactating rats: effect of intrabursal injection of prolactin antiserum, prolactin and LH. Endocrinology 94, 829-834.

Yoshinaga, K., N. R. Moudgal and R. O. Greep (1971). Progestin secretion by the ovary in lactating rats: effect of LH-antiserum, LH and prolactin. Endocrinology 88, 1126-1130. 